\title{
PERCEPCION DEL ESTUDIANTADO DE ENSEÑANZA BASICA SOBRE EL ROL DEL ESTADO, LAS INSTITUCIONES PUBLICAS, LA DEMOCRACIA, LA CIUDADANIA Y LOS DERECHOS DE LAS MUJERES Y DE LOS INMIGRANTES*
}

\author{
Perceptions of elementary students about the role of the State, of Public \\ Institutions, Democracy, Citizenship, Women Rights and ImMigRants Rights \\ Percepções de estudantes do ensino básico sobre o papel do Estado, das instituições \\ públicas, da cidadania, dos direitos das mulheres e dos direitos dos imigrantes.
}

\author{
Carlos Muñoz Labraña**, Nelson Vásquez Lara ${ }^{* * *}$, Leonora Reyes Jedlicki ${ }^{* * * *}$ \\ Universidad de Concepción $^{* *}$, Pontificia Universidad Católica de Valparaíso ${ }^{* * *}$, Universidad de Chile ${ }^{* * * *}$
}

\begin{abstract}
RESUMEN
Esta investigación informa sobre algunas concepciones y actitudes que posee el estudiantado de octavo año de enseñanza básica de tres regiones de Chile sobre el Estado, la democracia y la sociedad civil. Los resultados demostraron que los estudiantes, al finalizar el segundo ciclo básico, asocian el rol del Estado a cuestiones más sociales que políticas; manifiestan una gran desconfianza en los partidos políticos; están cada vez más conscientes de sus derechos y de la importancia de reconocer el derecho de los demás; no vinculan la ciudadanía con la participación en un partido político sino con acciones desarrolladas en el ámbito social y están más proclives a la igualdad de responsabilidades entre hombres y mujeres.
\end{abstract}

Palabras clave: Percepciones, democracia, mujeres, inmigrantes.

\begin{abstract}
This research reports some views and attitudes held by the eighth-graders of elementary education in three regions of Chile. These views and attitudes are related to the State, Democracy and the Civil Society. The results showed that at the end of their studies in the secondary cycle of elementary school the students associate the role of the State with more social issues rather than with political ones. In addition, they highly mistrust political parties and they are increasingly aware of their rights and of the importance of recognizing other people's rights. Furthermore, they do not link citizenship to the participation in a political party, but they link it to actions developed in the social field. Moreover, they are inclined to perceive men and women having equal responsibilities.
\end{abstract}

Key words: Perceptions, democracy, women, inmigrante.

\section{RESUMO}

Esta pesquisa informa sobre algumas opiniões e atitudes que os alunos de oitavo grau do ensino básico possuem sobre o Estado, a democracia e a sociedade civil em três regiões do Chile. Os resultados demonstraram que os alunos, ao finalizar o segundo ciclo básico, relacionam o papel do Estado a questões sociais e não tanto a questões políticas; manifestam desconfianza aos partidos políticos; são cada vez mais conscientes dos seus direitos e da importância de reconhecer os direitos dos outros; não relacionam cidadanía com a participação num partido político, mas com ações desenvolvidas no âmbito social e estão mais proclives à igualdade de responsabilidades entre homens e mulheres.

Palavras chave: Percepções, democracia, mulheres, imigrantes.

* Este artículo forma parte de una investigación financiada por el Centro de Investigación Avanzada en Educación (CIAE), en su concurso 2008 (FONDAP No 11-2008), que tuvo como objetivo evaluar las conceptualizaciones, actitudes y acciones cívicas de los estudiantes al finalizar el segundo ciclo de Enseñanza Básica. 


\section{INTRODUCCION}

En 1999 más de 5.500 estudiantes de octavo año básico de Chile participaron en un estudio internacional de educación cívica realizado por la International Association for the Evaluation of Educational Achievement. El objetivo fue medir los conocimientos cívicos de los estudiantes chilenos al terminar la Educación Básica.

Los resultados obtenidos por los estudiantes no fueron satisfactorios para las autoridades públicas (MINEDUC, 2004). Estos fueron evaluados en función de temas que hasta ese momento eran ignorados por los programas de estudio, definidos en 1981 durante el gobierno militar. La debilidad de los resultados fue explicada por la inexistencia de oportunidades de aprendizaje que favorecieran en el mundo escolar la comprensión de su importancia (MINEDUC, 2004). Luego de algunos años de implementación de un nuevo Marco Curricular, ha sido necesario realizar un nuevo estudio que investigue las opiniones del estudiantado acerca del Estado, las instituciones públicas, la democracia, la ciudadanía y los derechos de las mujeres e inmigrantes.

Aunque la bibliografía especializada reconoce que la escuela no es el único contexto de educación, y que el profesorado tampoco es un agente exclusivo para enseñar dichas temáticas a los estudiantes -pues la familia, los medios de comunicación y la sociedad en su conjunto también desempeñan un importante rol educativo (Bolívar A., 2007)-, no es menos cierto que en esta tarea la educación formal tiene responsabilidades, entre las que destacan el modelo de ciudadano que se desea construir, la definición de las condiciones que facultan para ejercer derechos, la explicitación de obligaciones, capacidades, actitudes y comportamientos de los jóvenes y los modos de vida deseables en la sociedad contemporánea (Martínez J., 2003).

Esta investigación ha sido posible gracias al aporte del Centro de Investigación Avanzada en Educación (CIAE), en su concurso 2008 (FONDAP No 11-2008). Su objetivo fundamental ha sido describir el rol que el estudiantado asigna al Estado, la confiabilidad que asignan a las instituciones públicas, lo que consideran bueno y malo para la democracia, lo que entienden por un buen ciudadano y finalmente su opinión sobre los derechos políticos y económicos de las mujeres e inmigrantes.

\section{MARCO TEORICO}

Existe una amplia literatura especializada, en español y en el mundo anglosajón, que aborda las particularidades, las consideraciones -teóricas y prácticas- y los desafíos sociales y educativos que implican las concepciones que los estudiantes tienen del sistema democrático. En ella se destaca su carácter polisémico, multiacentual, cultural y universal (Marco B., 2003; Rosanvallon P., 1999). Amplia es la bibliografía que aborda, desde la ciencia política, el derecho y la historia, el rol del Estado en democracia y la confianza que tienen los ciudadanos sobre el gobierno, las instituciones republicanas, los partidos políticos y la vida pública en general. Estas investigaciones han indicado que en América Latina, por ejemplo, los ciudadanos tienen poca confianza en los partidos políticos y que dicha confianza depende de la eficacia de los gobiernos a nivel nacional para desarrollar políticas sectoriales (Corral, 2008). De esta forma, se advierte que en los ciudadanos latinoamericanos el rol del Estado se evalúa positivamente cuando es capaz 
de generar un número significativo de empleos (Seligson, 2008). Al mismo tiempo, otros estudios indican que la confianza que los ciudadanos entregan a las instituciones sigue siendo importante y crece en la medida que las instituciones políticas son capaces de cumplir sus metas, preparando y usando adecuadamente los recursos disponibles, además de orientar tales metas hacia el bienestar de los ciudadanos (Segovia, 2008).

Asimismo, tales estudios surgen desde diferentes corrientes teórico-filosóficas y varias investigaciones están vinculadas a la historia política y a la modernidad de las sociedades occidentales (Marshall, T., 1998). También están ligadas a las transformaciones políticas que experimentan dichas sociedades a lo largo del tiempo y al rol que cumplen los ciudadanos en ella (Garcés M., 2006; Arrau A., 2002). Se ha profundizado en la imposibilidad de las personas de ser reducidas a una dimensión exclusivamente política (González G., 1999; Bustamante J., 2001), o en el impedimento de ser promovidos a través de decretos, procesos educativos formales (Andrade M. y Miranda C., 2000; Cerda A. M., Egaña M. L., Magendzo A., Santa Cruz E. y Varas R., 2004; Cox C., Jaramillo R., Reimers F., 2005), o la posibilidad de ser construidos socialmente (Olivares C., 1996).

Tales características implican un enorme desafío desde el punto de vista societario y han sido especialmente relevantes para Chile luego de la recuperación de su democracia. El nuevo estatus político permitió una adecuación del marco jurídico a nuevas orientaciones de la realidad, iniciándose de este modo una interesante -aunque inacabada-preocupación por el estado del arte de la participación y la formación ciudadana de sus habitantes.

Aun cuando la legitimidad del régimen democrático en construcción nunca estuvo en duda, el sistema necesitó durante varios años de una continua actualización del consenso y de su legitimidad. Por un lado, se requería más eficiencia de las políticas públicas y, por otro, una efectividad real de la participación política, social, cultural y económica de los ciudadanos. Relevantes fueron los estudios que indagaron en algunas concepciones y prácticas democráticas de la sociedad civil en diferentes grupos etarios (Garcés M., Valdés A., 1999; Márquez F., Sanhueza A., De Ferrari M., 2001; Geber M., 2007; PNUD, 2002; CERC, 2002). Lo mismo ocurrió con aquellas investigaciones que focalizaron su interés en el mundo educativo.

Es precisamente en el ámbito educativo donde se han realizado los mayores esfuerzos de los últimos años. Se ha buscó por varios medios superar los graves inconvenientes heredados del gobierno militar. Se restableció la situación precedente a la reforma educativa de los años sesenta, definiendo una asignatura de Educación Cívica y Economía en la Enseñanza Media ${ }^{1}$ y en Educación Básica los contenidos quedaron asociados al área de Historia y Ciencias Sociales (MINEDUC, 1998).

Como es fácil de comprender, durante el gobierno militar el currículo fue deficitario desde el punto de vista de los conceptos clave asociados a una cultura política democrática. Esto quedó plenamente demostrado en la medición internacional de 1999. Un tercio de las preguntas de conocimiento de esta medición no fueron estudiadas por los jóvenes en los programas de estudio de Educación Básica anteriores a la Reforma. No figuraban temáticas como la Declaración de los Derechos Humanos, las amenazas y oportunidades de un sistema democrático, las acciones ilegales de una organización política, las fun-

Estas asignaturas se distribuían en educación Cívica en $3^{\text {er }}$ Año Medio, con dos horas semanales y Economía en $4^{\circ}$ Año Medio, también con dos horas a la semana. 
ciones y responsabilidades de los partidos políticos, el valor de la mayoría y el respeto a las minorías, etc. (MINEDUC, 2004).

Las definiciones curriculares en materia de formación ciudadana diseñadas por el gobierno militar estuvieron vigentes hasta el año 1997 para el primer ciclo básico $\left(1^{\circ}\right.$ a $4^{\circ}$ Básico) y por la modalidad de implementación gradual de la reforma curricular, más allá de 1999 en los cursos superiores de la Enseñanza Media. Esto permitió a las autoridades ministeriales de la época explicar los poco auspiciosos resultados obtenidos por los estudiantes en la Prueba Internacional de 1999. El contexto político y social, surgido durante la Transición a la Democracia en los primeros años de los noventa, demandó de la educación formal, específicamente del currículum escolar, un reforzamiento e incorporación de varios contenidos relacionados con el funcionamiento de un régimen democrático y el desarrollo de habilidades y actitudes que aseguraran y fortalecieran los principios y los valores fundamentales de una sociedad democrática moderna (MINEDUC, 2004). Fue así como en el año 1996 se aprobó el Marco Curricular de la Educación General Básica, comenzando su implementación en el primer nivel básico en el año 1997. A partir de entonces el nuevo Marco Curricular para la Enseñanza Básica introdujo -de manera explícita- objetivos fundamentales (O.F.) y contenidos mínimos obligatorios (C.M.O.), que abarcaron los distintos aspectos y dimensiones que considera la Formación Ciudadana en la actualidad ${ }^{2}$.

El nuevo Marco Curricular persigue:

- Termina con el concepto de "Educación Cívica", entendido hasta entonces como conocimientos sobre el Estado y el sistema político, y acuña la denominación "Formación Ciudadana", que incluye conocimientos, habilidades y actitudes necesarias para ser coherentes con una forma de vida e institucionalidad democráticas ${ }^{3}$. Se define como foco el conocimiento del sistema político democrático y sus instituciones, y profundiza temáticas centrales de la historia política reciente, a saber: Derechos Humanos; autoritarismo y transición a la democracia, así como aspectos de la ciudadanía moderna como son la relación con el medio ambiente, el manejo social de la ciencia y la tecnología, las habilidades de manejo crítico de la información y actitudes como la responsabilidad social. En este enfoque son tan importantes los conocimientos sobre el sistema político como las capacidades cognitivas y sociales para ejercer efectivamente la ciudadanía.

- Propone que los objetivos y contenidos relacionados con la Formación Ciudadana sean transversales y los instala en las asignaturas de Historia y Ciencias Sociales desde $1^{\text {er }}$ Año de la Enseñanza Básica a $4^{\circ}$ Año de la Enseñanza Media ${ }^{4}$.

2 En lo sucesivo cada año se incluyó un nuevo grado o curso al proceso de reforma, completándose el ciclo el año 2002 cuando se incorporó al proceso el $8^{\circ}$ Año Básico. En el caso de la Educación Media, el nuevo Marco Curricular fue aprobado en 1998 y los nuevos programas de estudio fueron implementados, un grado por año, entre 1999 y 2002

3 Habilidades de pensamiento tales como la capacidad de establecer reflexiones críticas y formular opiniones, y habilidades de realización tales como hacer acciones en pro de la comunidad y valores, entre estos, pluralismo, solidaridad, respeto por el otro, valoración de la democracia, valoración de los derechos humanos.

4 En la Educación General Básica: Comprensión del Medio Natural, Social y Cultural ( $1^{\circ}$ a $4^{\circ}$ Año Básico), Estudio y Comprensión de la Sociedad ( $5^{\circ}$ a $8^{\circ}$ Año Básico). En la Educación Media: Historia y Ciencias Sociales ( $1^{\circ}$ a $4^{\circ}$ Medio). 
- Incorpora de manera complementaria el desarrollo de habilidades y actitudes que favorecen la democracia y la Formación Ciudadana en otras tres asignaturas del plan de estudio: Lenguaje y Comunicación, Orientación y Filosofía.

- Define unos Objetivos Fundamentales Transversales (OFT), que explicitan un conjunto de valores, actitudes y habilidades relevantes para la democracia y la ciudadanía, los que deben ejecutarse tanto a través de los contenidos de las asignaturas, como en otros espacios escolares que favorezcan que los estudiantes pongan en práctica los aprendizajes logrados (Consejo de Curso, debates estudiantiles, Centro de Alumnos, etc.).

Las nuevas orientaciones introducidas en el currículum escolar aspiran a que los estudiantes se desarrollen como hombres y mujeres libres y socialmente responsables. Se desea que ellos sean, a la vez, competentes en el ejercicio de la ciudadanía y el fortalecimiento de la democracia. Para esto se plantea que deben conocer y comprender el rol del Estado y de las instituciones públicas, los derechos y deberes que implica la vida en democracia identificando lo que es bueno y malo para ella, y lo que se espera de un buen ciudadano, incluyendo la participación responsable en actividades comunitarias, el reconocimiento de la legitimidad de diversos puntos de vista sobre la realidad social y la valoración de principios básicos de libertad, igualdad, justicia, pluralismo y respeto a los derechos humanos en general (MINEDUC, 1998) ${ }^{5}$.

Asimismo, uno de los desafíos preferentes que asumió el nuevo marco legal fue la inclusión de los derechos y de las prácticas de grupos excluidos o postergados como las mujeres y los emigrantes. El objetivo fue que el estudiantado valorara las diferencias de cualquier tipo para "aprender a vivir juntos" (Delors J., 1996), lo que implica la comprensión del otro como un "ser legítimo" y el desarrollo de nuevas formas de convivencia basadas en el pluralismo, el entendimiento mutuo y las relaciones democráticas (Hirmas, 2009). De allí que se buscó proporcionar los elementos necesarios para ejercer plenamente la ciudadanía, contribuir a una cultura de la paz, transformar las estructuras de la sociedad y hacer que estas sean sensibles a las diferencias culturales, haciendo que la problemática de la interculturalidad pudiera residir en todos los sectores de la sociedad, dado que sus actores subalternos no eran los únicos obligados a conocer la cultura de los actores dominantes (Zavala V., 2005).

También, las innovaciones efectuadas han implicado la incorporación de nuevas temáticas, cuyos elementos curriculares se introducen de manera transversal a lo largo del proceso de educación y desde las etapas más tempranas de la infancia, para desarrollar nuevos contenidos y determinados valores. Lo que resulta coherente con el enfoque maximalista descrito por la bibliografía (Crick B. 2002), que ha buscado que el estudiantado se sienta ciudadano y un activo transformador de su realidad.

Tal como fue la experiencia de otros países que asumieron esta opción, caracterizados por estar en posesión de una democracia más madura ${ }^{6}$, el objetivo fue abrir una brecha

6 La Educación Cívica impartida a través de una sola asignatura especializada es la forma predominantemente aceptada por el profesorado de los países de reciente democratización en Europa del este; mientras que la forma adoptada por la reforma curricular chilena -integrada a Ciencias Sociales y a otras asignaturas- es la propia de la mayoría de las democracias más maduras. Aunque Inglaterra, luego del Informe de la Comisión Crick, en 1998, hizo obligatoria en la Enseñanza Media una asignatura de Ciudadanía. Ver Crick, B. (2002). La enseñanza de la ciudadanía y de la democracia en Gran Bretaña, Ministerio de Educación de ColombiaBritish Council, Educación Integral, Año 11, N 15, junio 2002. 
epistemológica en el sistema educativo chileno orientado tradicionalmente a estructuras curriculares basadas en lógicas disciplinares, situación creada en una tradición cultural de hace siglos (MINEDUC, 2004; Imbernón F., Majó J., Mayer M., Mayor F., Menchú R. y Tedesco J.C., 2002).

No obstante lo anterior y a pesar de las innovaciones curriculares efectuadas, la investigación educacional ha revelado que la participación y la acción política convencional son hechos que aparecen desvalorados en las opiniones de los estudiantes (Montero M., 1995) y que los estudiantes tienden a discriminar a las mujeres, a sus compañeros aymaras o mapuches de cualquier sexo (Edwards V., 1995), así como a los estudiantes de sectores populares (Hevia R., Hirmas C., Treviño E. \& Marambio P., 2005). Además, en la literatura reciente se reconoce que las concepciones de los estudiantes respecto al Estado y las instituciones públicas, la democracia y la ciudadanía y finalmente de los derechos de las mujeres e inmigrantes depende, como de ningún otro factor, de lo que ocurre en la escuela y lo que hace el profesorado (Cerda A. M., Egaña M. L., Magendzo A., Santa Cruz E. y Varas R., 2004), pues son ellos quienes en última instancia traducen el currículo declarado en currículo aplicado.

Sin embargo, a pesar de la importancia del profesorado, la investigación educacional demuestra que el espacio y el tiempo curricular que ocupan los conocimientos que responden a la racionalidad instrumental, sobrepasan con creces a los conocimientos que apuntan a una racionalidad axiológica y comunicativa tendiente a formar sujetos de derechos (Magendzo, 2004). Al mismo tiempo, existen aún otras evidencias que establecen que este componente de la reforma educativa es uno de los menos comprendidos por los docentes y poco trabajados en las prácticas pedagógicas (Egaña L., 2003), lo que estaría poniendo en tela de juicio la capacidad del sistema escolar para promover conocimientos, habilidades y disposiciones ciudadanas. Esta situación lleva a plantear a otros autores que si no se intencionan iniciativas explícitas acerca de la temática en el sistema escolar, especialmente en torno al sentido de la formación ciudadana, a los contenidos y las concepciones que sustentan las prácticas de los docentes en el aula, se hace muy difícil avanzar (Cerda A. M.; Egaña L., Magendzo A., Santa Cruz E., Varas R., 2004). Tal dificultad fue constatada por la Comisión de Formación Ciudadana (2004), la que planteó que uno de los principales desafíos era ir más allá de la simple ilustración acerca de ciertos derechos. Se requería un énfasis de los atributos, virtudes y valores que hacen a una persona un buen ciudadano, puesto que este concepto, así como otros, atiende precisamente a las disposiciones del carácter y a las destrezas intelectuales y prácticas que constituyen un ciudadano reflexivo, respetuoso y participativo.

Las aprehensiones de la Comisión de Formación Ciudadana (2004) se reflejan claramente en los resultados obtenidos en otra investigación efectuada en establecimientos de enseñanza básica de la Octava Región de nuestro país (Muñoz C., Victoriano R., 2009). En esa reciente indagación se constata que el profesorado que dicta la asignatura "Estudio y comprensión de la sociedad" en Octavo Año Básico, no intenciona de manera expresa las temáticas relacionadas con formación ciudadana en sus clases, no se sienten interpelados por ellas y considera que no cuentan con las herramientas mínimas para realizar con éxito su tarea de enseñanza-aprendizaje.

Otro estudio etnográfico realizado en una escuela de Santiago (UNESCO, 2005) evidenció que es la cultura escolar la que reproduce la convivencia social en general y en ocasiones está marcada por la violencia, el desprecio y el desinterés por el otro. Esto 
explicaría también la existencia de una convivencia escolar atravesada por las burlas, las descalificaciones, el racismo, el resentimiento, el machismo y la discriminación de la mujer. La discriminación étnica se manifestaría a través de la burla y la ridiculización de los rasgos físicos asociados a lo indígena, al color de la piel y al apellido (Hevia R, Hirmas C., Treviño E., \& Marambio P., 2005).

\section{METODOLOGIA}

La metodología usada en la investigación fue de carácter cuantitativa y exploratoria. El instrumento utilizado fue parte de la encuesta de conceptualizaciones, actitudes y acciones utilizada en la prueba de la International Association for the Evaluation of Educational Achievement (IEA), aplicada en Chile en 1999, cuyos ítems fueron liberados en el 2003. La encuesta fue aplicada a estudiantes de Octavo Año Básico de 18 colegios ubicados en tres regiones diferentes del país ( 6 en Bíobío, 6 en Valparaíso y 6 en la Región Metropolitana).

Las variables de interés se relacionaron con los conocimientos y actitudes del estudiantado respecto del Estado y las instituciones públicas, la democracia y la ciudadanía, y finalmente en relación a los derechos de las mujeres e inmigrantes. El muestreo se realizó considerando como unidades los cursos provenientes de los colegios escogidos al azar y en forma no proporcional.

Al igual que la prueba aplicada en 1999, la investigación parte de la base que la educación ciudadana en general -y las temáticas que aborda la investigación en particular-, fue incorporada por el estudiante y lo compenetra en la vida cotidiana y en situaciones de enseñanza-aprendizaje. Para ello sigue el modelo octogonal de Amadeo, Torney-Purta, Lehmann, Husfeldt y Nikolova, en el que el estudiantado aparece al centro circundado por distintos "portadores", cada uno de los cuales aporta desde sus particulares puntos de vista a sus diferentes concepciones.

El modelo utilizado fue consensuado por los países participantes en el Estudio Internacional de 1999 y se sustenta en la teoría de la psicología ecológica del desarrollo y en la teoría cognitiva contextual. En el primer caso, los portadores (agencias) impactan al individuo a través de las relaciones cara a cara, siendo ejemplos de ello la familia, la escuela, el grupo de amigos (dentro y fuera de la sala de clase), la comunidad formal e informal y los medios de comunicación y la televisión. En el octágono más externo, dentro del cual están estos procesos que relacionan a la sociedad y al individuo, se encuentran los procesos, las instituciones y los valores políticos, económicos y educacionales o comunicacionales; la estructura de oportunidades y el sistema de estratificación socioeconómica; valores e instituciones religiosas; valores relativos a participación social (individualismo /colectivismo); la posición internacional del país, y los héroes, símbolos y narrativas nacionales o comunitarias. Cada uno de ellos impacta en la forma en que estas ocho dimensiones se reflejan en el discurso público y, en cierta medida, toma en cuenta las acciones y reacciones de los otros portadores y las características de los individuos (MINEDUC, 2004).

En el segundo, es decir, la teoría cognitiva, el conocimiento consistiría en la capacidad para participar en las prácticas de la comunidad, para utilizar sus herramientas y para participar en los discursos de la sociedad, es decir, para interactuar e intercomunicarse, afectando y siendo afectado por los otros. 


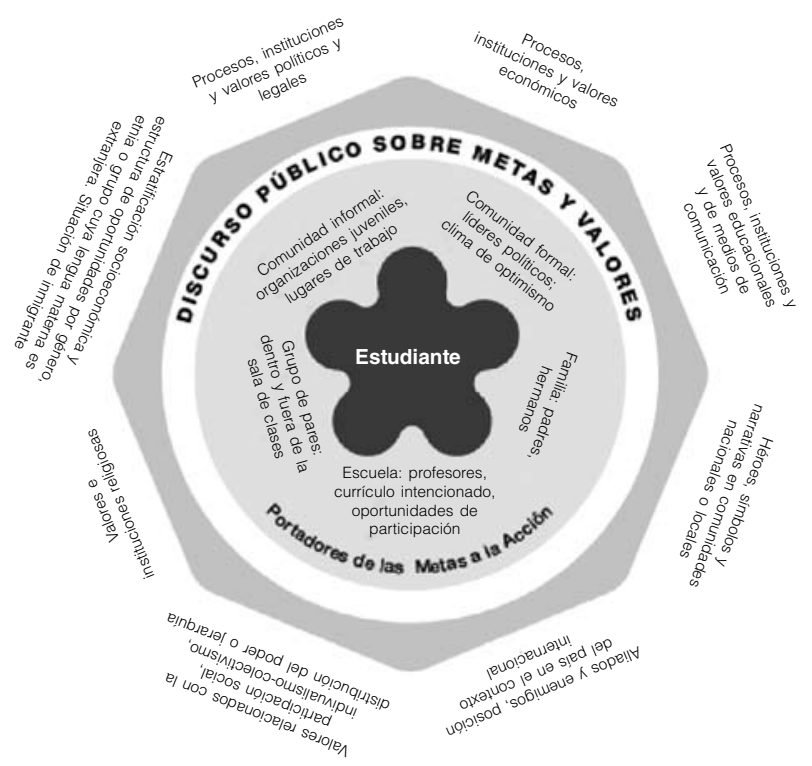

Fuente: Amadeo, J., Torney-Purta, J., Lehmann, R., Husfeldt, V. and Nikolova, R.: Civic knowledge and Engagement. An IEA study of upper secondary students in sixteen countries. IE A, 2002. En Estudio Internacional de Educación Cívica. MINEDUC 2004.

Ambos enfoques sugieren que los jóvenes se mueven de la participación periférica a la central en varias comunidades superpuestas (escuela/barrio), de tal manera que la socialización no consiste en que los adultos enseñen sino que la comunidad misma rodea y crea las situaciones o contextos para desarrollar los conocimientos y la identidad del joven (MINEDUC, 2004). Lo anterior hace que el estudio no sólo reconozca la importancia de la escuela en estas materias, sino que también distinga la influencia que pueden ejercer otros portadores, como los especificados.

\section{RESULTADOS}

Con el propósito de tener un punto de referencia de los resultados obtenidos, es importante consignar que en la prueba aplicada en 1999 quedó en evidencia que el estudiantado chileno que cursaba en ese momento Octavo Año Básico, poseía bajos niveles de conocimiento de contenidos cívicos y de las habilidades interpretativas asociadas, lo que se tradujo en un desconocimiento manifiesto respecto al rol del Estado y las instituciones públicas, la democracia y los derechos humanos, así como un déficit en las habilidades para interpretar lo que es bueno o malo para la democracia y lo que debe hacer un buen ciudadano, siendo el reconocimiento de los derechos de las mujeres e inmigrantes el ámbito notoriamente más bajo en este nivel (MINEDUC, 2004). 
Los resultados presentados en este escrito, si bien no pueden ser comparables estadísticamente con el estudio de 1999, tienen el objetivo de orientar el debate y abrir nuevas líneas de investigación que permitan analizar con más exactitud cómo ha sido la implementación de la reforma educacional en materia de formación ciudadana.

\section{ROL DEL ESTADO Y CONFIANZA EN LAS INSTITUCIONES PUBLICAS}

La Tabla $\mathrm{N}^{\circ} 1$ ofrece un panorama de lo que el estudiantado de Octavo Año Básico entiende como las principales responsabilidades que posee el Estado. Sobre estas temáticas la encuesta indica que existe un alto consenso entre el estudiantado y entre las diferentes regiones del país. Para los jóvenes, los principales roles que debe asumir el Estado son "asegurar salud básica para todos" (97\%), "asegurar a los ancianos un nivel de vida adecuado" (97\%), "asegurar igualdad de oportunidades políticas para hombres y mujeres" (95\%), "controlar la contaminación del medio ambiente" (95\%), y finalmente "garantizar la paz y la estabilidad dentro del país" (95\%).

Las responsabilidades que acaparan menor consenso entre el estudiantado son aquellas según las cuales el Estado debería "proporcionar el apoyo que necesitan las industrias para su crecimiento (79\%), y "reducir diferencias de ingresos y bienes entre las personas" $(77 \%)$.

\section{Tabla $N^{o} 1$}

Porcentaje de acuerdo y muy de acuerdo con las afirmaciones en la Encuesta asociadas a las responsabilidades del Estado, por Región y su promedio

\begin{tabular}{|l|l|c|c|c|c|}
\hline & \multicolumn{1}{|c|}{$\begin{array}{c}\text { ¿Qué responsabilidades } \\
\text { debería tener el Estado? }\end{array}$} & \multicolumn{3}{c|}{ REGION } \\
\hline & Pregunta & Promedio & Biobí & Valparaíso & Metropolitana \\
\hline C.1 & Garantizar un trabajo para quien lo desee. & $94 \%$ & $96 \%$ & $94 \%$ & $93 \%$ \\
\hline C.2 & Mantener los precios controlados. & $94 \%$ & $96 \%$ & $93 \%$ & $93 \%$ \\
\hline C.3 & Asegurar salud básica para todos. & $97 \%$ & $99 \%$ & $96 \%$ & $97 \%$ \\
\hline C.4 & Asegurar a los ancianos un nivel de vida adecuado. & $97 \%$ & $98 \%$ & $97 \%$ & $97 \%$ \\
\hline C.5 & $\begin{array}{l}\text { Proporcionar el apoyo que necesitan las industrias } \\
\text { para su crecimiento. }\end{array}$ & $79 \%$ & $76 \%$ & $83 \%$ & $77 \%$ \\
\hline C.6 & $\begin{array}{l}\text { Asegurar a los desempleados un nivel de vida } \\
\text { adecuado. }\end{array}$ & $90 \%$ & $94 \%$ & $88 \%$ & $89 \%$ \\
\hline C.7 & $\begin{array}{l}\text { Reducir diferencias de ingresos y bienes entre } \\
\text { las personas. }\end{array}$ & $77 \%$ & $75 \%$ & $76 \%$ & $79 \%$ \\
\hline C.8 & Asegurar una educación mínima gratuita para todos. & $92 \%$ & $94 \%$ & $87 \%$ & $95 \%$ \\
\hline C.9 & $\begin{array}{l}\text { Asegurar igualdad de oportunidades políticas para } \\
\text { hombres y mujeres. }\end{array}$ & $95 \%$ & $98 \%$ & $92 \%$ & $94 \%$ \\
\hline C.10 & Controlar la contaminación del medio ambiente. & $95 \%$ & $94 \%$ & $94 \%$ & $96 \%$ \\
\hline C.11 & Garantizar la paz y la estabilidad dentro del país. & $95 \%$ & $95 \%$ & $93 \%$ & $96 \%$ \\
\hline C.12 & $\begin{array}{l}\text { Promover la honestidad y las conductas morales } \\
\text { entre las personas del país. }\end{array}$ & $88 \%$ & $91 \%$ & $86 \%$ & $87 \%$ \\
\hline
\end{tabular}

Fuente: Conocimientos, habilidades y disposiciones ciudadanas de los estudiantes de Octavo Año Básico FONDAP 11-2008. 
En relación a los resultados por género, la Tabla $\mathrm{N}^{\mathrm{o}} 2$ presenta las preguntas en que existen diferencias significativas (valor $\mathrm{p}$ entre 0,01 y 0,05 ) y altamente significativas $(\mathrm{p}<0,01)$ entre ambos sexos.

\section{Tabla $N^{\circ} 2$}

Preguntas con diferencias altamente significativas y altamente significativas por género

\begin{tabular}{|l|l|c|c|c|}
\hline & ¿Qué responsabilidades debería tener el Estado? & & & \\
\hline & Pregunta & Masculino & Femenino & $\mathrm{p}$ \\
\hline C.2 & Mantener los precios controlados. & $90 \%$ & $95 \%$ & 0,0283 \\
\hline C.4 & Asegurar a los ancianos un nivel de vida adecuado. & $96 \%$ & $99 \%$ & 0,0269 \\
\hline C.10 & Controlar la contaminación del medio ambiente. & $93 \%$ & $97 \%$ & 0,0339 \\
\hline C.11 & Garantizar la paz y estabilidad dentro del país. & $94 \%$ & $98 \%$ & 0,0271 \\
\hline
\end{tabular}

Fuente: Conocimientos, habilidades y disposiciones ciudadanas de los estudiantes de Octavo Año Básico FONDAP 11-2008.

Respecto a la confianza que posee el estudiantado en las instituciones públicas, la Tabla $\mathrm{N}^{\circ} 3$ señala un panorama de la frecuencia con que el estudiantado de Octavo Básico se muestra de acuerdo y muy de acuerdo en relación a la confiabilidad de algunas instituciones, no existiendo diferencias significativas por sexo.

En la tabla se destaca una cierta homogeneidad de los resultados en las distintas regiones participantes en el estudio. Se indica cuáles son las instituciones en que más confían: la policía (74\%) y la escuela (77\%). Esta última es la institución que en promedio resulta más confiable para los estudiantes.

La institución menos confiable para el estudiantado son los partidos políticos (30\%). Bajo es el porcentaje de confianza del gobierno central (47\%), del gobierno municipal $(53 \%)$ y del Congreso (53\%).

\section{DEMOCRACIA Y CIUDADANIA}

Lo que el estudiantado de Octavo Año Básico entiende por democracia queda consignado en la Tabla $\mathrm{N}^{\mathrm{o}}$ 4. Para los jóvenes es bueno o muy bueno para la democracia, "cuando todos tienen derecho a expresar sus opiniones libremente" (96\%), "cuando las personas reclaman sus derechos políticos y sociales (84\%), "cuando los partidos políticos tienen normas que apoyan a las mujeres para que lleguen a ser dirigentes políticas" (92\%), "cuando los ciudadanos tienen el derecho a elegir libremente a sus dirigentes políticos" (92\%), "cuando existen diversos tipos de organizaciones que permiten a las personas participar en ellas" (93\%), y finalmente "cuando las personas protestan pacíficamente en contra de una ley que consideran injusta" (83\%).

Asimismo, hubo un alto consenso en afirmar que es muy malo o malo para la democracia "cuando el gobierno no pone restricciones a las empresas privadas" (84\%), 


\section{TablaN $^{o} 3$}

Porcentaje de acuerdo y muy de acuerdo con las afirmaciones en la Encuesta asociadas a la frecuencia con que el estudiantado puede confiar en algunas Instituciones, por Región y su promedio

\begin{tabular}{|l|l|c|c|c|c|}
\hline & \multicolumn{1}{|c|}{$\begin{array}{c}\text { ¿Con qué frecuencia puedes } \\
\text { confiar en cada una de } \\
\text { las siguientes instituciones? }\end{array}$} & \multicolumn{4}{c|}{ REGIÓN } \\
\hline & Pregunta & Promedio & Biobío & Valparaíso & Metropolitana \\
\hline D.1 & El gobierno central. & $47 \%$ & $42 \%$ & $46 \%$ & $52 \%$ \\
\hline D.2 & El gobierno municipal. & $53 \%$ & $56 \%$ & $50 \%$ & $54 \%$ \\
\hline D.3 & Los tribunales de justicia. & $62 \%$ & $71 \%$ & $60 \%$ & $54 \%$ \\
\hline D.4 & La policía. & $74 \%$ & $82 \%$ & $69 \%$ & $71 \%$ \\
\hline D.5 & Las noticias en la televisión. & $62 \%$ & $67 \%$ & $67 \%$ & $53 \%$ \\
\hline D.6 & Las noticias en la radio. & $56 \%$ & $62 \%$ & $57 \%$ & $49 \%$ \\
\hline D.7 & Noticias en los periódicos. & $65 \%$ & $65 \%$ & $66 \%$ & $64 \%$ \\
\hline D.8 & Los partidos políticos. & $30 \%$ & $28 \%$ & $27 \%$ & $36 \%$ \\
\hline D.9 & Las Naciones Unidas. & $55 \%$ & $55 \%$ & $49 \%$ & $62 \%$ \\
\hline D.10 & Las escuelas. & $77 \%$ & $78 \%$ & $69 \%$ & $83 \%$ \\
\hline D.11 & El Congreso. & $53 \%$ & $49 \%$ & $46 \%$ & $63 \%$ \\
\hline D.12 & La gente que vive en Chile. & $57 \%$ & $52 \%$ & $55 \%$ & $63 \%$ \\
\hline
\end{tabular}

Fuente: Conocimientos, habilidades y disposiciones ciudadanas de los estudiantes de Octavo Año Básico FONDAP 11-2008.

"cuando se prohíbe hablar en reuniones públicas a personas que critican al gobierno" (84\%) y "ccuando empresarios adinerados tienen más influencia en el gobierno que otras personas" ( $85 \%)$.

Resulta también interesante destacar que en ciertos ítems no hubo consenso absoluto en los estudiantes encuestados. Ellos tuvieron opiniones dispares en relación a lo bueno o lo malo para la democracia "cuando las diferencias de ingresos y bienes entre ricos y pobres son pequeñas" (56\%), "cuando los periódicos están libres de todo control estatal" (51\%), "cuando los partidos políticos tienen opiniones distintas en materias importantes"(53\%), "cuando las personas participan en partidos políticos para ejercer influencia en el gobierno" (58\%) y finalmente "cando se confía plenamente en los dirigentes del gobierno" (54\%).

Al analizar los resultados obtenidos por Región, llama la atención la relativa homogeneidad de los resultados, registrándose sólo algunas diferencias significativas entre los establecimientos educacionales de una región u otra $(\mathrm{p}<0,01)$. Por ejemplo, los estudiantes tuvieron opiniones dispares en relación a lo bueno o lo malo para la democracia "cuando las diferencias de ingresos y bienes entre ricos y pobres son pequeñas", 
"cuando los periódicos están libres de todo control estatal", "cuando existe separación entre Iglesia y Estado", y finalmente "cuando las mujeres protestan por leyes que son injustas para ellas y éstas se cambian".

\section{Tabla $N^{\circ} 4$}

Porcentaje de acuerdo y muy de acuerdo con las afirmaciones en la Encuesta relativas a lo que es bueno y malo para la democracia, por Región y su promedio

\begin{tabular}{|c|c|c|c|c|c|}
\hline & \multirow{2}{*}{\begin{tabular}{|l|}
$\begin{array}{c}\text { ¿Qué es bueno y qué es malo } \\
\text { para la democracia? }\end{array}$ \\
Pregunta
\end{tabular}} & \multicolumn{4}{|c|}{ REGION } \\
\hline & & Promedio & Biobío & Valparaíso & Metropolitana \\
\hline A. 1 & $\begin{array}{l}\text { Cuando todos tienen el derecho a expresar } \\
\text { sus opiniones libremente. }\end{array}$ & $96 \%$ & $96 \%$ & $97 \%$ & $94 \%$ \\
\hline A. 2 & $\begin{array}{l}\text { Cuando las diferencias de ingresos y bienes } \\
\text { entre ricos y pobres son pequeñas. }\end{array}$ & $56 \%$ & $45 \%$ & $63 \%$ & $59 \%$ \\
\hline A. 3 & $\begin{array}{l}\text { Cuando los dirigentes políticos en el poder, } \\
\text { dan trabajo a miembros de sus familias en } \\
\text { el sector público. }\end{array}$ & $37 \%$ & $41 \%$ & $32 \%$ & $38 \%$ \\
\hline A. 4 & $\begin{array}{l}\text { Cuando los periódicos están libres de todo } \\
\text { control estatal. }\end{array}$ & $51 \%$ & $46 \%$ & $43 \%$ & $63 \%$ \\
\hline A. 5 & $\begin{array}{l}\text { Cuando el gobierno no pone restricciones a } \\
\text { las empresas privadas. }\end{array}$ & $16 \%$ & $14 \%$ & $16 \%$ & $19 \%$ \\
\hline A. 6 & $\begin{array}{l}\text { Cuando una empresa es dueña de todos los } \\
\text { periódicos. }\end{array}$ & $23 \%$ & $15 \%$ & $29 \%$ & $26 \%$ \\
\hline A. 7 & $\begin{array}{l}\text { Cuando las personas reclaman sus derechos } \\
\text { políticos y sociales. }\end{array}$ & $84 \%$ & $88 \%$ & $80 \%$ & $85 \%$ \\
\hline A. 8 & $\begin{array}{l}\text { Cuando se supone que los inmigrantes } \\
\text { deben dejar el idioma y las costumbres de } \\
\text { su país de origen. }\end{array}$ & $20 \%$ & $12 \%$ & $27 \%$ & $21 \%$ \\
\hline A. 9 & $\begin{array}{l}\text { Cuando los partidos políticos tienen normas } \\
\text { que apoyan a las mujeres para que lleguen } \\
\text { a ser dirigentes políticos. }\end{array}$ & $92 \%$ & $94 \%$ & $85 \%$ & $96 \%$ \\
\hline A. 10 & $\begin{array}{l}\text { Cuando se prohíbe hablar en reuniones } \\
\text { públicas a las personas que critican al } \\
\text { gobierno. }\end{array}$ & $16 \%$ & $11 \%$ & $23 \%$ & $13 \%$ \\
\hline A. 11 & $\begin{array}{l}\text { Cuando los ciudadanos tienen el derecho a } \\
\text { elegir libremente a sus dirigentes políticos. }\end{array}$ & $92 \%$ & $95 \%$ & $86 \%$ & $95 \%$ \\
\hline A. 12 & $\begin{array}{l}\text { Cuando los políticos ejercen influencia en } \\
\text { las cortes de justicia y en los jueces. }\end{array}$ & $29 \%$ & $31 \%$ & $34 \%$ & $21 \%$ \\
\hline A. 13 & $\begin{array}{l}\text { Cuando existen diversos tipos de orga- } \\
\text { nizaciones que permiten a las personas } \\
\text { participar en ellas. }\end{array}$ & $93 \%$ & $95 \%$ & $94 \%$ & $91 \%$ \\
\hline
\end{tabular}




\begin{tabular}{|c|c|c|c|c|c|}
\hline & ¿Qué es bueno y qué es malo & \multicolumn{4}{|c|}{ REGION } \\
\hline & Pregunta & Promedio & Biobío & Valparaíso & Metropolitana \\
\hline A. 14 & $\begin{array}{l}\text { Cuando existe separación entre Iglesia y } \\
\text { Estado. }\end{array}$ & $38 \%$ & $30 \%$ & $33 \%$ & $52 \%$ \\
\hline A. 15 & $\begin{array}{l}\text { Cuando a los jóvenes se les obliga a par- } \\
\text { ticipar en actividades que benefician a la } \\
\text { comunidad. }\end{array}$ & $45 \%$ & $42 \%$ & $48 \%$ & $44 \%$ \\
\hline A. 16 & $\begin{array}{l}\text { Cuando a cada persona se le asegura un } \\
\text { ingreso mínimo. }\end{array}$ & $65 \%$ & $64 \%$ & $70 \%$ & $61 \%$ \\
\hline A. 17 & $\begin{array}{l}\text { Cuando los partidos políticos tienen opinio- } \\
\text { nes distintas en materias importantes. }\end{array}$ & $53 \%$ & $57 \%$ & $49 \%$ & $54 \%$ \\
\hline A. 18 & $\begin{array}{l}\text { Cuando las personas participan en parti- } \\
\text { dos políticos para ejercer influencia en el } \\
\text { gobierno. }\end{array}$ & $58 \%$ & $55 \%$ & $61 \%$ & $58 \%$ \\
\hline A. 19 & $\begin{array}{l}\text { Cuando las mujeres protestan por leyes que } \\
\text { son injustas para ellas y éstas se cambian. }\end{array}$ & $78 \%$ & $72 \%$ & $76 \%$ & $85 \%$ \\
\hline A. 20 & $\begin{array}{l}\text { Cuando todos los canales de televisión } \\
\text { presentan la misma opinión política. }\end{array}$ & $41 \%$ & $47 \%$ & $37 \%$ & $38 \%$ \\
\hline A. 21 & $\begin{array}{l}\text { Cuando las personas se niegan a obedecer } \\
\text { una ley que viola los derechos humanos. }\end{array}$ & $31 \%$ & $22 \%$ & $36 \%$ & $35 \%$ \\
\hline A. 22 & $\begin{array}{l}\text { Cuando se prohíbe a los periódicos publicar } \\
\text { artículos que puedan ofender a extranjeros } \\
\text { o grupos étnicos. }\end{array}$ & $65 \%$ & $68 \%$ & $62 \%$ & $65 \%$ \\
\hline A. 23 & $\begin{array}{l}\text { Cuando empresarios adinerados tienen } \\
\text { más influencia en el gobierno que otras } \\
\text { personas. }\end{array}$ & $15 \%$ & $14 \%$ & $19 \%$ & $11 \%$ \\
\hline A. 24 & $\begin{array}{l}\text { Cuando se confía plenamente en los diri- } \\
\text { gentes del gobierno. }\end{array}$ & $54 \%$ & $49 \%$ & $54 \%$ & $58 \%$ \\
\hline A. 25 & $\begin{array}{l}\text { Cuando las personas protestan pacífica- } \\
\text { mente en contra de una ley que consideran } \\
\text { injusta. }\end{array}$ & $83 \%$ & $79 \%$ & $84 \%$ & $87 \%$ \\
\hline
\end{tabular}

Fuente: Conocimientos, habilidades y disposiciones ciudadanas de los estudiantes de Octavo Año Básico FONDAP 11-2008.

En relación a los resultados por género, la Tabla $\mathrm{N}^{\circ} 5$ presenta las preguntas en que existen diferencias significativas (valor $\mathrm{p}$ entre $0,01 \mathrm{y} 0,05)$ y altamente significativas $(\mathrm{p}<0,01)$ entre ambos sexos. 


\section{Tabla $N^{o} 5$}

Preguntas con diferencias altamente significativas y altamente significativas por género.

\begin{tabular}{|l|l|c|c|c|}
\hline & Qué es bueno y malo para la democracia & \multicolumn{2}{|c|}{} \\
\cline { 2 - 4 } & Pregunta & Masculino & Femenino & p \\
\hline A.12 & $\begin{array}{l}\text { Cuando los políticos ejercen influencia en las cortes de } \\
\text { justicia y en los jueces. }\end{array}$ & $28 \%$ & $17 \%$ & 0,0140 \\
\hline A.18 & $\begin{array}{l}\text { Cuando las Personas Participan en partidos políticos } \\
\text { para ejercer influencia en el gobierno. }\end{array}$ & $61 \%$ & $42 \%$ & 0,0001 \\
\hline A.19 & $\begin{array}{l}\text { Cuando las mujeres protestan por leyes que son injustas } \\
\text { para ellas, y éstas se cambian. }\end{array}$ & $76 \%$ & $85 \%$ & 0,0091 \\
\hline A.22 & $\begin{array}{l}\text { Cuando se prohíbe a los periódicos publicar artículos } \\
\text { que puedan ofender a extranjeros o grupos étnicos. }\end{array}$ & $63 \%$ & $74 \%$ & 0,0169 \\
\hline A.23 & $\begin{array}{l}\text { Cuando empresarios adinerados tienen más influencia } \\
\text { en el gobierno que otras personas. }\end{array}$ & $15 \%$ & $8 \%$ & 0,0263 \\
\hline A.24 & $\begin{array}{l}\text { Cuando se confía plenamente en los dirigentes del } \\
\text { gobierno. }\end{array}$ & $61 \%$ & $48 \%$ & 0,0110 \\
\hline A.25 & $\begin{array}{l}\text { Cuando las personas protestan pacíficamente contra una } \\
\text { ley que consideran injusta. }\end{array}$ & $80 \%$ & $88 \%$ & 0,0204 \\
\hline
\end{tabular}

Fuente: Conocimientos, habilidades y disposiciones ciudadanas de los estudiantes de Octavo Año Básico FONDAP 11-2008.

Las diferencias altamente significativas obtenidas por género permiten inferir que las niñas se muestran más sensibles ante aquellas situaciones que han sido catalogadas como buenas para la democracia, especialmente donde se promueve la igualdad de las personas y el respeto a sus derechos. Siendo algunas situaciones en las que se distorsiona el uso del poder, las que acaparan mayor inclinación entre los varones.

Respecto al concepto de ciudadanía que se describe en el estudio, éste se concentró en la percepción de los estudiantes sobre las acciones específicas que caracterizan a un buen ciudadano adulto. El análisis realizado a los datos reflejó la existencia de dos dimensiones, las que a su vez dieron origen a dos escalas: Ciudadanía convencional y Ciudadanía como movimiento social.

La primera está asociada a la participación en actividades políticas formales, tradicionalmente asociadas a la democracia, como la participación en un partido político, votar en una elección, informarse sobre temas políticos a través de los medios de comunicación, demostrar respeto hacia los representantes políticos, participar en discusiones políticas y conocer sobre la historia del propio país.

La segunda está vinculada a la participación en actividades relacionadas con la vida en comunidad, el fortalecimiento de la sociedad civil, la pertenencia a grupos que promueven diversas causas, como participar en una protesta pacífica, en actividades de beneficio para la comunidad, de promoción de derechos humanos y de protección del medio ambiente. 
La Tabla $\mathrm{N}^{\circ} 6$ ofrece un panorama de los ítems que componen la escala de ciudadanía convencional. En ella destaca la existencia de dos grupos de ítems claramente identificables, con independencia del área geográfica. El primer grupo indica aquellas actividades ciudadanas convencionales más valoradas por el estudiantado, entre las que se cuentan conocer la historia de su país (83\%), votar en cada elección (79\%), demostrar respeto por los representantes del gobierno $(78 \%)$ y finalmente informarse sobre los temas políticos en el periódico (75\%). El segundo grupo de ítems da cuenta de aquellas actividades ciudadanas convencionales menos importantes para el estudiantado, como la participación en discusiones políticas (43\%) y la participación en un partido político (37\%).

\section{Tabla $N^{o} 6$}

Porcentaje de los ítems de la escala de ciudadanía convencional

\begin{tabular}{|l|l|c|c|c|c|}
\hline & Un adulto que es buen ciudadano... & \multicolumn{4}{|c|}{ REGION } \\
\hline & Pregunta & Promedio & Biobío & Valparaíso & Metropolitana \\
\hline B.2 & Vota en cada elección. & $79 \%$ & $87 \%$ & $77 \%$ & $72 \%$ \\
\hline B.3 & Participa en un partido político. & $37 \%$ & $42 \%$ & $29 \%$ & $39 \%$ \\
\hline B.6 & Conoce la historia de su país. & $83 \%$ & $85 \%$ & $80 \%$ & $83 \%$ \\
\hline B.8 & $\begin{array}{l}\text { Se informa sobre temas políticos en el } \\
\text { periódico, en la radio o en la televisión. }\end{array}$ & $75 \%$ & $76 \%$ & $74 \%$ & $76 \%$ \\
\hline B.10 & $\begin{array}{l}\text { Demuestra respeto por los representan- } \\
\text { tes del gobierno. }\end{array}$ & $78 \%$ & $84 \%$ & $79 \%$ & $71 \%$ \\
\hline B.12 & Participa en discusiones políticas. & $43 \%$ & $36 \%$ & $50 \%$ & $43 \%$ \\
\hline
\end{tabular}

Fuente: Conocimientos, habilidades y disposiciones ciudadanas de los estudiantes de Octavo Año Básico FONDAP 11-2008.

La Tabla $N^{o} 7$ muestra un panorama de los ítems que componen la escala de ciudadanía como movimiento social. En ella se aprecia menos dispersión y porcentajes más altos en cada uno de los ítems que componen esta escala al compararlas con los ítems agrupados en torno a la ciudadanía convencional. La tabla destaca la importancia que el estudiantado asigna a la participación en actividades para proteger el medio ambiente (92\%) y aquellas destinadas a beneficiar a su comunidad (87\%). 


\section{Tabla $N^{\circ} 7$}

Porcentaje de los ítemes de la escala de ciudadanía como movimiento social

\begin{tabular}{|l|l|c|c|c|c|}
\hline & Un adulto que es buen ciudadano... & \multicolumn{4}{|c|}{ REGION } \\
\hline & Pregunta & Promedio & Biobío & Valparaíso & Metropolitana \\
\hline B.5 & $\begin{array}{l}\text { Participaría en una protesta pacífica } \\
\text { contra una ley que considera injusta. }\end{array}$ & $82 \%$ & $89 \%$ & $78 \%$ & $79 \%$ \\
\hline B.9 & $\begin{array}{l}\text { Participa en actividades que benefician a } \\
\text { las personas de su comunidad. }\end{array}$ & $87 \%$ & $89 \%$ & $85 \%$ & $86 \%$ \\
\hline B.11 & $\begin{array}{l}\text { Participa en actividades que promueven } \\
\text { los derechos humanos. }\end{array}$ & $85 \%$ & $82 \%$ & $86 \%$ & $86 \%$ \\
\hline B.13 & $\begin{array}{l}\text { Participa en actividades para proteger el } \\
\text { medio ambiente. }\end{array}$ & $92 \%$ & $95 \%$ & $92 \%$ & $90 \%$ \\
\hline
\end{tabular}

Fuente: Conocimientos, habilidades y disposiciones ciudadanas de los estudiantes de Octavo Año Básico FONDAP 11-2008.

Los resultados de ambas escalas demuestran como los jóvenes adhieren de manera mucho más significativa al concepto de ciudadanía como movimiento social. Es preocupante el bajo nivel de importancia que asignan a la participación en discusiones políticas y en sus instituciones asociadas. No es que los jóvenes no valoren la participación, sino que hacen una diferencia entre la participación política convencional y aquella que tiene un significado más social, que al parecer ven más cercana.

Respecto al género, sólo en dos preguntas existen diferencias significativas (valor $\mathrm{p}$ entre 0,01 y 0,05$)$ y altamente significativas $(\mathrm{p}<0,01)$ entre ambos sexos, las que han sido consignadas en la Tabla $\mathrm{N}^{\circ}$ 8. Esto permite inferir que las niñas son más respetuosas de la autoridad y, al mismo tiempo, se sienten más comprometidas con los derechos humanos.

\section{Tabla $N^{o} 8$}

Items con diferencias significativas y altamente significativas por género

\begin{tabular}{|l|l|c|c|c|}
\hline & Un adulto que es buen ciudadano... & \multicolumn{3}{|c|}{} \\
\hline & Pregunta & Masculino & Femenino & $\mathrm{p}$ \\
\hline B.10 & Demuestra respeto por los representantes del gobierno. & $75 \%$ & $86 \%$ & 0,0031 \\
\hline B.11 & $\begin{array}{l}\text { Participa en actividades que promueven los derechos } \\
\text { humanos. }\end{array}$ & $81 \%$ & $88 \%$ & 0,0473 \\
\hline
\end{tabular}

Fuente: Conocimientos, habilidades y disposiciones ciudadanas de los estudiantes de Octavo Año Básico FONDAP 11-2008. 


\section{DERECHOS DE LAS MUJERES E INMIGRANTES}

La Tabla N ${ }^{\circ} 9$ ofrece una visión de lo que el estudiantado de Octavo Año Básico opina respecto a los derechos políticos y económicos de las mujeres. Para ellos, "las mujeres deberían ser candidatas al Congreso y participar en el gobierno al igual que los hombres" (95\%), "las mujeres deberían tener los mismos derechos que los hombres en todos los aspectos" (97\%) y "hombres y mujeres que desempeñan el mismo trabajo deberían recibir la misma remuneración" (94\%). Es muy bajo el porcentaje que asiente que "las mujeres tienen menos probabilidades que los hombres de acceder a buenos trabajos en Chile" (28\%), "cuando hay escasez de trabajo, los hombres tienen más derecho a tener empleo que las mujeres" (21\%) y finalmente que "los hombres están mejor calificados que las mujeres para ser dirigentes políticos" (25\%). No existe consenso en que "las mujeres deberían mantenerse al margen de la política" (52\%).

\section{Tabla $N^{\circ} 9$}

Porcentaje de acuerdo y muy de acuerdo con las afirmaciones en la Encuesta asociadas a la opinión del estudiantado en relación a los derechos políticos y económicos de las mujeres, por Región y su promedio.

\begin{tabular}{|l|l|c|c|c|c|}
\hline \multirow{2}{*}{} & Oportunidades 1 & \multicolumn{3}{|c|}{ REGION } \\
\cline { 2 - 6 } & Pregunta & Promedio & Bíobío & Valparaíso & Metropolitana \\
\hline F.6 & $\begin{array}{l}\text { Las mujeres tienen menos probabilidades } \\
\text { que los hombres de acceder a buenos } \\
\text { trabajos en Chile. }\end{array}$ & $28 \%$ & $22 \%$ & $36 \%$ & $25 \%$ \\
\hline G.1 & $\begin{array}{l}\text { Las mujeres deberían ser candidatas al } \\
\text { Congreso y participar en el gobierno al } \\
\text { igual que los hombres. }\end{array}$ & $95 \%$ & $98 \%$ & $94 \%$ & $92 \%$ \\
\hline G.4 & $\begin{array}{l}\text { Las mujeres deberían tener los mismos } \\
\text { derechos que los hombres en todos los } \\
\text { aspectos. }\end{array}$ & $97 \%$ & $99 \%$ & $97 \%$ & $96 \%$ \\
\hline G.6 & $\begin{array}{l}\text { Las mujeres deberían mantenerse al } \\
\text { margen de la política. }\end{array}$ & $52 \%$ & $46 \%$ & $57 \%$ & $53 \%$ \\
\hline G.9 & $\begin{array}{l}\text { Cuando hay escasez de trabajo, los hom- } \\
\text { bres tienen más derecho a tener empleo } \\
\text { que las mujeres. }\end{array}$ & $21 \%$ & $13 \%$ & $23 \%$ & $27 \%$ \\
\hline G.11 & $\begin{array}{l}\text { Hombres y mujeres que desempeñan el } \\
\text { mismo trabajo deberían recibir la misma } \\
\text { remuneración. }\end{array}$ & $94 \%$ & $97 \%$ & $93 \%$ & $91 \%$ \\
\hline G.13 & $\begin{array}{l}\text { Los hombres están mejor calificados que } \\
\text { las mujeres para ser dirigentes políticos. }\end{array}$ & $25 \%$ & $28 \%$ & $20 \%$ & $28 \%$ \\
\hline
\end{tabular}

Fuente: Conocimientos, habilidades y disposiciones ciudadanas de los estudiantes de Octavo aAñoBásico FONDAP 11-2008. 
Respecto al género, es el ámbito en el cual existen mayores diferencias significativas (valor $\mathrm{p}$ entre 0,01 y 0,05$)$ y altamente significativas $(\mathrm{p}<0,01)$ entre ambos sexos, como se demuestra en la Tabla $\mathrm{N}^{\circ} 10$. Esto permite inferir que las niñas detectan con mayor facilidad las situaciones de injusticia que afectan a las mujeres y a las minorías, y además son más proclives a la libertad de expresión.

\section{Tabla $N^{\circ} 10$}

Items con diferencias significativas y altamente significativas por género

\begin{tabular}{|l|l|c|c|c|}
\hline & Oportunidades 1 & & & \\
\hline & Pregunta & Masculino & Femenino & $\mathrm{p}$ \\
\hline G.1 & $\begin{array}{l}\text { Las mujeres deberían ser candidatas al Congreso y parti- } \\
\text { cipar del gobierno igual que los hombres. }\end{array}$ & $91 \%$ & $97 \%$ & 0,0164 \\
\hline G.3 & $\begin{array}{l}\text { Se debería prohibir que los miembros de grupos antide- } \\
\text { mocráticos se presenten en programas de televisión en } \\
\text { donde expongan sus ideas. }\end{array}$ & $51 \%$ & $35 \%$ & 0,0015 \\
\hline G.4 & $\begin{array}{l}\text { Las mujeres deberían tener los mismos derechos que los } \\
\text { hombres en todos los aspectos. }\end{array}$ & $94 \%$ & $98 \%$ & 0,0188 \\
\hline G.5 & $\begin{array}{l}\text { Todos los grupos étnicos deberían tener igualdad de } \\
\text { oportunidades para obtener buenos trabajos en Chile. }\end{array}$ & $94 \%$ & $98 \%$ & 0,0161 \\
\hline G.9 & $\begin{array}{l}\text { Cuando hay escasez de trabajo, los hombres tienen más } \\
\text { derecho que las mujeres a tener empleo. }\end{array}$ & $23 \%$ & $15 \%$ & 0,0308 \\
\hline G.10 & $\begin{array}{l}\text { Se debería prohibir que los miembros de grupos antide- } \\
\text { mocráticos sean candidatos a cargos públicos. }\end{array}$ & $49 \%$ & $37 \%$ & 0,0175 \\
\hline G.11 & $\begin{array}{l}\text { Hombres y mujeres que desempeñan el mismo trabajo } \\
\text { deberían recibir la misma remuneración. }\end{array}$ & $91 \%$ & $98 \%$ & 0,0010 \\
\hline G.13 & $\begin{array}{l}\text { Los hombres están mejor calificados que las mujeres } \\
\text { para ser dirigentes políticos. }\end{array}$ & $31 \%$ & $21 \%$ & 0,0228 \\
\hline
\end{tabular}

Fuente: Conocimientos, habilidades y disposiciones ciudadanas de los estudiantes de Octavo Año Básico FONDAP 11-2008.

Respecto a los derechos de los inmigrantes, la Tabla $\mathrm{N}^{\mathrm{o}} 11$ informa de la actitud del estudiantado de Octavo Año Básico hacia los inmigrantes. En ella se destaca la homogeneidad de las frecuencias fijadas entre el estudiantado en las distintas regiones del país.

Para el estudiantado "los inmigrantes deberían tener la oportunidad de mantener su idioma" (92\%), "los hijos de inmigrantes deberían tener las mismas oportunidades de educación que otros niños en el país" (96\%), "los inmigrantes deberían tener la oportunidad de mantener sus costumbres y estilo de vida" (90\%) y es muy bajo el porcentaje que está de acuerdo con que "se debería prohibir que los inmigrantes se involucren en actividades políticas (27\%). En las actitudes de los estudiantes existen consensos respecto a la conservación de la cultura de los inmigrantes, y el resguardo de su participación formal 
en la vida pública, aunque esta tendencia entra en tensión con preguntas relacionadas con la integración efectiva de ellos a aspectos culturales más cercanos, existiendo un alto porcentaje de estudiantes que se muestran a favor de afirmaciones como "deberíamos evitar que los extranjeros influyan en la cultura y tradiciones de Chile (60\%)", "si hay muchos inmigrantes, es difícil que los habitantes de un país sean unidos y patriotas" $(50 \%)$. Esta tendencia se evidencia con mayor fuerza en los hombres que en las mujeres Tabla $\mathrm{N}^{\mathrm{o}} 12$.

\section{Tabla $N^{\circ} 11$}

Porcentaje de acuerdo y muy de acuerdo con las afirmaciones en la Encuesta asociadas a la actitud del estudiantado hacia los inmigrantes, por Región y su promedio

\begin{tabular}{|c|c|c|c|c|c|}
\hline & Inmigrantes & & & REGION & \\
\hline & Pregunta & Promedio & Biobío & Valparaíso & Metropolitana \\
\hline E.12 & $\begin{array}{l}\text { Deberíamos evitar que los extranjeros } \\
\text { influyan en la cultura y tradiciones de } \\
\text { Chile. }\end{array}$ & $63 \%$ & $61 \%$ & $63 \%$ & $64 \%$ \\
\hline H.1 & $\begin{array}{l}\text { Los inmigrantes deberían tener la oportu- } \\
\text { nidad de mantener su idioma. }\end{array}$ & $92 \%$ & $92 \%$ & $91 \%$ & $92 \%$ \\
\hline H.2 & $\begin{array}{l}\text { Los hijos de inmigrantes deberían tener } \\
\text { las mismas oportunidades de educación } \\
\text { que otros niños en el país. }\end{array}$ & $96 \%$ & $99 \%$ & $95 \%$ & $95 \%$ \\
\hline H.3 & $\begin{array}{l}\text { Los inmigrantes que han vivido en un } \\
\text { país por varios años, deberían tener la } \\
\text { oportunidad de votar en las elecciones. }\end{array}$ & $86 \%$ & $91 \%$ & $80 \%$ & $87 \%$ \\
\hline H.4 & $\begin{array}{l}\text { Los inmigrantes deberían tener la opor- } \\
\text { tunidad de mantener sus costumbres y } \\
\text { estilo de vida. }\end{array}$ & $90 \%$ & $91 \%$ & $89 \%$ & $89 \%$ \\
\hline H.5 & $\begin{array}{l}\text { Los inmigrantes deberían tener los } \\
\text { mismos derechos que todos los demás } \\
\text { habitantes de ese país. }\end{array}$ & $88 \%$ & $91 \%$ & $84 \%$ & $90 \%$ \\
\hline H.6 & $\begin{array}{l}\text { Se debería prohibir que los inmigrantes } \\
\text { se involucren en actividades políticas. }\end{array}$ & $27 \%$ & $23 \%$ & $30 \%$ & $27 \%$ \\
\hline H.7 & $\begin{array}{l}\text { Si hay muchos inmigrantes, es difícil que } \\
\text { los habitantes de un país sean unidos y } \\
\text { patriotas. }\end{array}$ & $50 \%$ & $50 \%$ & $54 \%$ & $47 \%$ \\
\hline H.8 & $\begin{array}{l}\text { Todos los países deberían aceptar refugia- } \\
\text { dos que tratan de huir de las guerras o las } \\
\text { persecuciones políticas en otros países. }\end{array}$ & $83 \%$ & $88 \%$ & $81 \%$ & $81 \%$ \\
\hline
\end{tabular}

Fuente: Conocimientos, habilidades y disposiciones ciudadanas de los estudiantes de Octavo Año Básico FONDAP 11-2008. 
Respecto al género, la Tabla $\mathrm{N}^{\mathrm{o}} 12$ da cuenta de aquellas preguntas en las cuales existen diferencias significativas (valor $\mathrm{p}$ entre 0,01 y 0,05 ) y altamente significativas $(\mathrm{p}<0,01)$ entre ambos sexos. Estos datos permiten inferir que las niñas tienden a tener actitudes más integradoras y solidarias hacia los inmigrantes que los varones, mostrándose más tolerantes y abiertas a las diferencias y a la inmigración que sus pares varones. Se puede inferir que esta tendencia da cuenta de la influencia de los roles sociales en las actitudes que presentan los estudiantes, pues no puede ser inferida de aspectos propiamente curriculares en la medida que las diferencias se dan entre estudiantes pares.

Tabla $N^{\circ} 12$

Items con diferencias significativas y altamente significativas por género

\begin{tabular}{|l|l|c|c|c|}
\hline & Oportunidades 1 & \multicolumn{3}{|c|}{} \\
\cline { 2 - 3 } & Pregunta & Masculino & Femenino & $\mathrm{p}$ \\
\hline H.1 & $\begin{array}{l}\text { Los inmigrantes deberían tener la oportunidad de man- } \\
\text { tener su idioma. }\end{array}$ & $88 \%$ & $94 \%$ & 0,0320 \\
\hline H.4 & $\begin{array}{l}\text { Los inmigrantes deberían tener la oportunidad de man- } \\
\text { tener sus costumbres y estilo de vida. }\end{array}$ & $84 \%$ & $93 \%$ & 0,0021 \\
\hline H.6 & $\begin{array}{l}\text { Se debería prohibir que los inmigrantes se involucren } \\
\text { en actividades políticas. }\end{array}$ & $33 \%$ & $22 \%$ & 0,0132 \\
\hline H.7 & $\begin{array}{l}\text { Si hay muchos inmigrantes es difícil que los miembros } \\
\text { de un país sean unidos y patriotas. }\end{array}$ & $53 \%$ & $37 \%$ & 0,0008 \\
\hline
\end{tabular}

Fuente: Conocimientos, habilidades y disposiciones ciudadanas de los estudiantes de Octavo Año Básico FONDAP 11-2008.

\section{CONCLUSIONES}

Esta investigación exploratoria sobre las conceptualizaciones y actitudes de los estudiantes de octavo básico, en tres regiones de Chile, permitió detectar qué está ocurriendo con los estudiantes en materia de formación ciudadana.

Hace diez años se pensó que las transformaciones curriculares proyectadas por el Ministerio de Educación eran suficientes para generar mejores y mayores aprendizajes entre los jóvenes. Hoy, los resultados preliminares de la investigación permiten aventurar que existen más factores influyendo en la calidad de los aprendizajes escolares, además de la focalización de innovaciones curriculares emprendida a fines de los noventa.

Los resultados demostraron que los estudiantes, al finalizar el segundo ciclo básico, asocian el rol del Estado a cuestiones más sociales que políticas, demandan efectividad de las políticas públicas y un mayor impacto en las vidas de las personas. Esto es muy coherente con estudios como el de Segovia, Have, González, Manzi y Carvacho que plantearon que los ciudadanos chilenos depositan mucha confianza en las instituciones políticas democráticas. Pero cuando enjuician dicha confianza indican que tal confianza es percibida en relación con la preparación y los recursos disponibles para 
cumplir las metas propuestas y en la medida que tales metas propicien el bienestar de los ciudadanos.

Del mismo modo, queda en evidencia en el estudio que los jóvenes tienen una gran desconfianza en los partidos políticos y en la capacidad de ellos de responder a las necesidades concretas de los individuos en la contingencia.

Los estudiantes encuestados están bastante conscientes de sus derechos y de la importancia de reconocer el derecho de los demás. Al parecer se está en presencia de una sociedad chilena que acepta a todos los ciudadanos y que es más tolerante con las diversidades culturales existentes en la sociedad. Tal reconocimiento de la diversidad puede ser un efecto positivo de las políticas públicas que insertaron la formación ciudadana en el currículo en forma transversal.

Otro resultado de la indagación es la relación que tienen los ciudadanos con la participación en los partidos políticos. Dicha relación es considerada de menor importancia. Los jóvenes prefieren las acciones desarrolladas por ellos mismos en el mundo social.

Por otro lado, una posible explicación a que se evidencien porcentajes más bajos que los esperados en las preguntas relacionadas con actitudes más abiertas frente a los distintos ámbitos de la participación de mujeres e inmigrantes, es que los contenidos, habilidades y actitudes medidas en los 8 vos años en formación ciudadana, todavía se vinculan más hacia temáticas relacionadas con los aspectos jurídicos y legales de democracia y participación, excepto en la finalización del programa de 8vo cuando se insta a los alumnos y alumnas a diseñar y llevar a cabo un proyecto grupal de acción social comunitaria en el que pueden experimentar la responsabilidad social e individual de la promoción de los Derechos Humanos y asegurar que éstos se cumplan (MINEDUC, 2004).

Asimismo, el hecho que los porcentajes de respuestas relacionadas con una actitud más abierta hacia los inmigrantes sean en general más bajos que frente a los derechos de las mujeres, constituye una "novedad" en términos de debate público del fenómeno de la inmigración en nuestro país. A pesar de que la cantidad de migrantes ha aumentado en forma exponencial entre 1992 y 2009, y Chile se ha transformado de ser un país que produce inmigrantes hacia ser un país que recibe inmigración, el debate sobre lo mismo está achatado, invisibilizado y muchas veces excluido del espacio público. Prueba de ello es la escasez de estudios relacionados con los impactos sociales y culturales de este fenómeno. Ello representa un desafío para la formación ciudadana en este segmento escolar.

Una posible explicación para la sensibilidad de las mujeres a temas relacionados con las injusticias que viven las mujeres y las minorías, es la de una actitud culturalmente más dispuesta a la acogida del que viene "de afuera". Sin embargo, esto no está exento de la prolongación de su identidad de género que se traslada a espacios como el de la escuela. Esto puede ser visto como una potencialidad pero también debiera explorarse sobre qué bases se funda esta actitud, si en cuanto a reconocimiento "del otro", o más bien es un rol impuesto por la tradición patriarcal. Queda pendiente, en este sentido, explorar hasta dónde la formación ciudadana en el currículum promueve cambios culturales que apunten a desarrollar una genuina actitud de reconocimiento "del otro" en hombres y mujeres.

Finalmente, una posible explicación a la diferencia en los porcentajes de respuestas afirmativas entre aquellas preguntas que hablaban de garantías formales para los inmigrantes, con aquellas que apelaban a una integración real de los mismos a la sociedad, el estudio nos señala que se ha avanzado en integrar elementos cognitivos a los jóvenes relacionados con la tolerancia y el respeto por los otros, pero que aún existe una deuda en términos prácticos y emotivos. 


\section{BIBLIOGRAFIA}

Amadeo, J., Torney-Purta, J., Lehmann, R., Husfeldt, V. and Nikolova, R. Civic knowledge and Engagement. An IEA study of upper secondary students in sixteen countries. IE A, 2002. En Estudio Internacional de educación Cívica. MINEDUC 2004.

Andrade, M. y Miranda, C., (2000). El concepto de ciudadanía en educación análisis semiótico de las representaciones sociales del concepto de ciudadanía en profesores mapuches y citadinos de educación general básica en Chile. Pontificia Universidad Católica de Chile Facultad de Educación programa de doctorado en Ciencias de la Educación.

Arrau, A. y Avendaño, O. (2002); La Hacienda Revivida: Democracia y Ciudadanía en el Chile de la Transición; FRASIS; Chile.

Bobbio, N. (1978). Democracia y Dictadura. Enciclopedia Einaudi. Italia

Bobbio, N. (1992). El futuro de la democracia. México. Fondo de Cultura Económica

Bolívar, A. (2007). Educación para la ciudadanía, Algo más que una asignatura; Editorial Graó; España.

Bustamante, J. (2001). Hacia la cuarta generación de Derechos Humanos: repensando la condición humana en la sociedad tecnológica. En Revista Iberoamericana de Ciencia, Tecnología, Sociedad e Innovación ISSN 1681-5645. № 1.

Carbonell, S. J. (2008). Una educación para mañana. Octaedro. España.

CEPAL (2000). Equidad, Desarrollo y Ciudadanía, Visión Global, Tomo I, Editorial Alfaomega, Colombia.

CERC (2002). Encuesta sobre participación ciudadana en Chile.

Cerda, A. M., Egaña, M. L., Magendzo, A., Santa Cruz, E. y Varas, R. (2004). El complejo camino de la formación ciudadana. Una mirada a las prácticas docentes; LOM. Chile.

Corral, M. (2008). Desconfianza en los partidos políticos en América Latina. Revista de Ciencia Política, Volumen 28, $\mathrm{N}^{\mathrm{o}}$ 2, pp. 195-202.

Correa, E. y Noé, M. (1998). Nociones de una Ciudadanía que crece. Chile. LOM.

Cox, C., Jaramillo, R. y Reimers, F. (2005). Educar para la Ciudadanía y la Democracia en las Américas: Una Agenda para la Acción. Banco Interamericano de Desarrollo. Departamento de Desarrollo Sostenible División de Estado, Gobernabilidad y Sociedad Civil Unidad de Educación.

Crick, B. (2002). La enseñanza de la ciudadanía y de la democracia en Gran Bretaña, Ministerio de Educación de Colombia-British Council, Educación Integral, Año 11, Nº 15, junio 2002.

Delors, J. (1996). La educación encierra un tesoro. Informe a la UNESCO de la comisión Internacional sobre la educación para el siglo XXI. Ediciones UNESCO, Madrid. Santillana.

Edwards, V. (1995). El Liceo por dentro. Estudio etnográfico sobre prácticas de trabajo en educación media. MINEDUC, Proyecto MECE-MEDIA, PIIE, Santiago, Chile.

Egaña, L. (2003). Reforma Educativa y Objetivos Fundamentales Transversales. Los dilemas de la innovación. PIIE, Santiago 2003.

Farcas, D. (1999). Ciudadanía en Chile: El desafío cultural del nuevo milenio; Departamento de Estudios, División de Organizaciones Sociales, Ministerio Secretaría General de Gobierno. Chile.

Garcés, M. (2006). Democracia y Ciudadanía en el MERCOSUR; LOM. Santiago de Chile.

Garcés, M., Valdés, A (1999). Estado del arte de la Participación ciudadana en Chile. Documento preparado para la OXFAM-GB. Santiago de Chile.

Garretón, M. A. (2007). Del Postpinochetismo a la Sociedad Democrática. Globalización y política en el Bicentenario. DEBATE, Chile.

Gerber, M. (2007). Estudio sobre el estado del arte de la investigación en participación ciudadana en Chile. Informe de resultados. Innovación y Ciudadanía. Corporación Participa. Santiago de Chile.

Giroux, H. (2003). La escuela y la lucha por la ciudadanía. Siglo XXI Editores. Tercera Edición. Buenos Aires, Argentina. 
Godoy, O. (1999). La transición chilena a la democracia: pactada. Estudios Públicos, 74. Santiago de Chile.

González, G. (1999). Derechos Humanos: La condición humana en la sociedad tecnológica. Madrid: Tecnos.

Hevia, R., Hirmas, C., Treviño, E. y Marambio, P (2005). Políticas Educativas de Atención a la Diversidad Cultural Brasil, Chile, Colombia, México y Perú. Vol. 1. UNESCO: Santiago.

Hirmas, C. (2009). Educación y diversidad cultural. Lecciones desde la práctica innovadora en América Latina. UNESCO: Santiago.

Imbernón, F., Maj, J., Mayer, M., Mayor, F., Menchú, R. y Tedesco J. C. (2002). Cinco ciudadanías para una nueva educación. Graó, España.

López, S. (1997). Ciudadanos reales e imaginarios: Concepciones, desarrollo y mapas de ciudadanía en el Perú; IDS: Instituto de diagnóstico y propuestas. Perú.

Magendzo, A. (2004). Educación y Ciudadanía: Construyendo ciudadanía desde el currículum oficial y la cotidianidad de la escuela. Una lectura desde la investigación. PIIE Seminario Internacional. Reformas Curriculares en los noventa y la construcción de ciudadanía.

Marco, S., Berta (2003). Educación para la ciudadanía. Un enfoque basado en el desarrollo de competencias transversales; Narcea; España.

Márquez, F., Sanhueza, A. y De Ferrari M., (2001). Participación ciudadana en la gestión pública. Santiago de Chile.

Marshall, T. (1998). Ciudadanía y Clase Social. Alianza Editorial. España.

Martínez, J. (2003). Ciudadanía, poder y educación; Graó. España.

MINEDUC (1998). Objetivos Fundamentales y Contenidos Mínimos Obligatorios de la Educación Media. Sector Historia y ciencias Sociales. Formación general, Santiago de Chile, pp. 99 y "Objetivos Fundamentales Transversales", p. 23.

MINEDUC (2004). Informe comisión Formación Ciudadana. Santiago.

MINEDUC (2004). Educación Cívica y el ejercicio de la Ciudadanía. Los estudiantes chilenos en el estudio internacional de educación Cívica. Santiago.

Montero, M. (1995). Modos alternativos de acción política. En Beaudoux, V., D’Adamo, O. \& Montero, M. Psicología de la acción política. Buenos Aires: Paidós.

Muñoz, C. y Victoriano R. (2009). El desafío de la Formación Ciudadana. Principios para un modelo de integración curricular en Lenguaje y Comunicación y Estudio y Comprensión de la Sociedad para la EGB. FONIDE F. 310894.

Olivares, C. (1996). Memoria Foro Género y Ciudadanía, La Paz. CIDEM REPEM/CEAAL; Bolivia. PNUD (2002). Desarrollo Humano en Chile. Fyrma Gráfica. Santiago de Chile.

Rosanvallon, P. (1999). La consagración del ciudadano. Historia del sufragio universal, Instituto Mora. México.

Segovia, C. (2008). Confianza en instituciones políticas en Chile: un modelo de los componentes centrales d juicio de confianza. Revista de Ciencia Política, volumen 28, № 2, pp. 39-60.

Seligson, M. (2008). El rol del Estado como creador de empleo. Revista de Ciencia Política, volumen $28, \mathrm{~N}^{\circ} 2$, pp. 209-218.

Terry, K. (2003). Democracia, Desarrollo y Estado de Derecho. Compiladores: Osvaldo Iazzetta, Guillermo O'Donnell y Jorge Vargas-Cullell, Democracia, desarrollo humano y ciudadanía. (Argentina: editorial Homo Sapiens, en coauspicio con el Programa de Naciones Unidas para el Desarrollo (PNUD).

UNESCO (2005). Diversidad Cultural y educación. Vol. 2: La discriminación y el pluralismo en la vida cotidiana de las escuelas: casos de Brasil, Chile, Colombia, México y Perú. UNESCO: Santiago.

Zavala, V. (2005): Hacia la construcción de un proceso educativo intercultural: elementos para el debate. Perú. Ministerio de Educación PROEDUCA-GTZ: Lima. 
